\title{
Are Home Based Pelvic Floor Muscle Exercises (PFMES) Effective in Prevention of Stress Urinary Incontinence During Pregnancy? A Randomized Controlled Trial
}

\author{
Maria Habib*, Irum Sohail, Mehak Asim Khan \\ Department of Obstetrics and Gynaecology, KRL Hospital, Islamabad, Pakistan.
}

\begin{abstract}
Objectives: To determine effectiveness of 8 weeks home based PFMEs in the prevention of stress urinary incontinence (SUI) during pregnancy and to see how many women were consistent with them.

Materials And Methods: This randomized controlled trial was conducted in the outpatient department (OPD) of Obstetrics/Gynaecology, Kahuta Research Laboratories (KRL) hospital, Islamabad during Nov, 2017 to Jan,2018. After fulfilling the inclusion/exclusion criteria, women were randomly divided into two groups. One group learned to perform PFMEs. A telephonic survey was conducted after 8 weeks and all the women in the study were asked about presence/absence of perceived urinary incontinence. Data were analysed using descriptive statistics.

Results: A total of 120 women were randomized into the study. Amongst those who were followed, $63.4 \%$ from intervention group didn't adhere to PFMEs and dropped out from study. A total of 42 women were analysed from both groups. Mean age was $25+-3$ years and mean gestational age was $23+-4$ weeks. Thirty nine percent were nullipara. Amongst women in the intervention group, majority were still continent after 8 weeks of PFMEs (86.6\%) and only few experienced SUI (13.4\%). However, when these women were matched with controls, fewer women as compared to intervention group were continent after 8 weeks $(55.6 \%)$.
\end{abstract}

Conclusion: Home based pelvic floor muscle exercises are very effective in prevention of stress urinary incontinence in only highly motivated patients.

Keywords: Kegel exercises, PFMEs, Pregnancy, Antenatal period, Urinary incontinence, Women, Prevention.

\section{INTRODUCTION}

Urinary incontinence (UI) has detrimental effects on women's health and quality of life (social, physical and psychological well being) along with placing a burden on health resources. The International Continence society (ICS) has defined urinary incontinence (UI) as uncontrolled urine leakage which is self evident and causes social and hygienic issues [1].

Different types of UI are: stress urinary incontinence (SUI), urge urinary incontinence (UUI) and mixed urinary incontinence (MUI). Amongst these, SUI is the commonest one. SUI is defined as involuntary loss of urine on increase in intra-abdominal pressure [2]. It is usually with jumping, walking, weight lifting, sneezing or coughing. Its pathophysiology is defect in position and support of the bladder and urethra leading to unintentional urine leakage as soon as the bladder pressure exceeds urethral pressure $[1,2]$.

The World Health Organisation (WHO) has classified urinary incontinence amongst the 10 major health issues currently being faced by women. Prevalence of UI as estimated by National Institute of Diabetes \& Digestive \& Kidney diseases

*Address correspondence to this author at the Department of Obstetrics and Gynaecology, KRL Hospital, Islamabad, Pakistan.

E-mail: mariahabibawan@gmail.com
(NIDDK) is $25-45 \%$. In reproductive age group, its prevalence is $7-35 \%$ while $9-39 \%$ in older age group [3]. Prevalence of UI in Pakistan is estimated to be $45 \%$ in pregnant and $10.6 \%$ in postpartum women $[4,5]$. The annual cost in the treatment of UI in United States (US) range from 16-65 billion dollars [6].

Pregnancy is amongst the top risk factors of UI. This is due to the decreased pelvic floor muscle function due to physiological changes of pregnancy. Pelvic floor muscle exercises (PFMEs) are effective for prevention and treatment of SUI in pregnancy. It has no reported side effects, is less time consuming and is cost effective. ICS advises PFMEs as the first line treatment for SUI [6].

According to National Institute of Clinical Excellence (NICE), all women should be advised PFMEs during their first pregnancy as a primary preventive method. Effectiveness of PFMEs is reported to be $75 \%$ if regularly performed [7]. In PFMEs, voluntary contraction of levator ani muscle is done which increases its tone and strength. It gives more control to the women over their perivaginal area [8].

Various studies have shown effectiveness of PFMEs during pregnancy especially supervised by physiotherapist or 
midwifes. There is uncertaintly regarding effectiveness of home based PFMEs during pregnancy. Moreover,no local data is available to assess the response of our pregnant population towards home based PFMEs as dedicated antenatal clinics are not available in our country. So the present study was conducted to determine effectiveness of 8 weeks home based PFMEs in the prevention of SUI during pregnancy and to see how many women were consistent with them.

\section{MATERIALS AND METHODS}

After taking ethical approval from hospital's ethics committee, this randomized controlled trial was conducted in the outpatient department (OPD) of Obstetrics/Gynaecology, Kahuta Research Laboratories (KRL) hospital, Islamabad. Recruitment of the participants started in Nov, 2017 and data was finalized by the end of Jan, 2018. Inclusion criteria were; booked at KRL hospital, between 14-28 weeks of gestation, educated atleast upto middle and continent at the time of recruitment into the study. Exclusion criteria were; current urinary tract infection (UTI) which was confirmed on routine urine examination and any symptoms of stress, urge or mixed urinary incontinence. After explaining objectives of the study, women attending the antenatal clinic were invited to participate in the study. A total of 120 women were recruited in the study after taking verbal informed consent. Maternal age, parity and gestational age were recorded in the data.

Women were randomly divided into two groups; intervention group and control group. At the beginning of intervention, women were educated about pelvic floor muscle exercises and their beneficial role by the researcher trainee. Then women in both groups learned how to perform contractions adequately.
After that, they were advised to perform 10 contractions twice a day at home for 8 weeks. No further examination or former testing were done to check for muscle strength.

Examples of advising exercises were: Contract your pelvic floor muscles for 10 seconds like you are trying to hold urine and then relax, squeeze your pelvic floor muscles while inhaling and relax while exhaling etc.

Women randomized in the control group didn't receive any intervention and they were just advised routine antenatal care.

A telephonic survey was done after 8 weeks and all the women in the study were asked about presence or absence of perceived stress urinary incontinence. If they were incontinent, frequency and volume of urine during incontinence episodes were asked and recorded. If they were continent, no further questions were asked. Those randomized to intervention groups were inquired; if they remained adhered to these exercises during this 8 weeks period? Those not adhered to the exercises ( 10 contractions twice daily) were excluded from the study.

However, all the women in control group also received education about PFMEs and encouraged for them at the end of study period.

Analysis was done using statistical package for social sciences (SPSS) version 21. Count and percentages were calculated using descriptive statistics.

\section{RESULTS}

A flow chart for the participants initially recruited in the study, their drop outs and final participants selected for analysis are shown (Fig. 1).

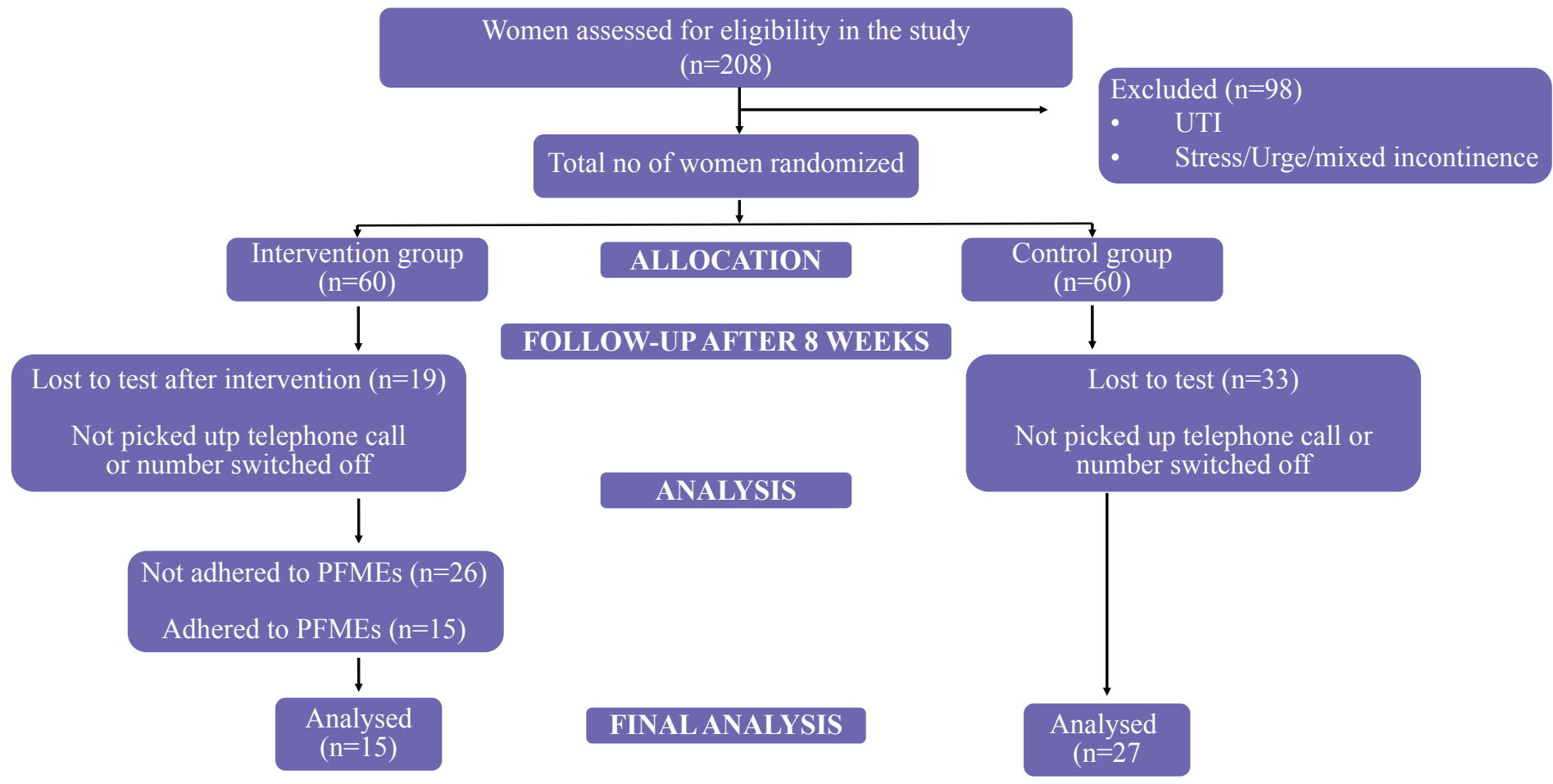

Fig. (1). Flow Chart of the Study Participants from Recruitment to Final Analysis. 
A total of 120 women were randomized into the study after fulfilling the inclusion/exclusion criteria. 60 women were randomly divided into the intervention group and these were matched with 60 controls. $31.6 \%$ women from the intervention group and 55\% women from the control group were lost to test and excluded from the study. Also many women from intervention group didn't adhere to PFMEs and dropped out from the study (63.4\%).

A total of 42 women were finally analysed. Mean age of the study participants was $25+-3$ years and mean gestational age was $23+-4$ weeks. Thirty nine percent of the study participants were nullipara.

A total of 15 women were analysed from intervention group. Majority were still continent after 8 weeks of PFMEs (86.6\%) and only few experienced SUI (13.4\%). However, when these women were matched with controls, fewer women as compared to intervention group were continent after 8 weeks (55.6\%) (Table 1).

Table 1. Response of Women after 8 Weeks of PFMES as Compared to Controls.

\begin{tabular}{|l|cc|cc|}
\hline $\begin{array}{c}\text { Continence status } \\
\text { after 8 weeks }\end{array}$ & \multicolumn{2}{|c|}{$\begin{array}{c}\text { Intervention } \\
\text { group }\end{array}$} & \multicolumn{2}{c|}{ Controls } \\
\hline Continent & 13 & $86.6 \%$ & 15 & $55.6 \%$ \\
\hline Incontinent & 2 & $13.4 \%$ & 12 & $44.4 \%$ \\
\hline Total & 15 & $100 \%$ & 27 & $100 \%$ \\
\hline
\end{tabular}

\section{DISCUSSION}

AThis study has highlighted that 8 weeks home based PFMEs were effective in the prevention of SUI during pregnancy in only highly motivated patients. Those who were consistent with PFMEs, less SUI was experienced after 8 weeks as compared to controls.

Earlier studies have shown that PFMEs were very effective in prevention of SUI. Stafne SN, et al. conducted a study on 855 antenatal women and concluded that those randomized to 12 weeks exercise programme were less likely to report UI as compared to controls [9]. This is in line with results of our study as those who remained adhered to 8 weeks exercise programme reported less UI. Similarly, results of cochrane database review involving 22 trials on 8485 women concluded that PFMEs were effective in prevention of SUI in both antenatal and postnatal period, and their protective effect lasts upto six months after delivery $[10,11]$.

A Quasi experimental study was conducted by Sangsawang $\mathrm{B}$, et al. on 66 incontinent women by offering 6 weeks PFMEs and highlighted that severity of incontinence symptoms was significantly reduced [12]. Woodley SJ, et al. reported that regular PFMEs can treat SUI in both antenatal and postpartum patients [13]. Those who properly perform PFMEs, they are 17 times more likely to get cure of incontinence symptoms
[14]. These studies have highlighted that PFMEs help to strengthen the pelvic floor muscles and consequently their sphincteric action. This is how regular PFMEs help in prevention of SUI in pregnancy.

Whether women could properly contract their pelvic muscles after detailed information was not included in this study as many women were reluctant for perineal examination. Previous studies have shown that many women are not able to perform PFMEs in a correct way during their first visit and they need more thorough information regarding their pelvic floor muscles and guidance for correct performance [15].

A Swedish study by Alhund et al. on home based PFMEs has shown very few drop outs from their exercise programme which is in contrast to the results of our study as majority of the participants dropped out from our study because of non adherence to recommended exercises [16].

The strengths of our study were; it was a randomized controlled trial, all the study participants whether in intervention or control group were educated about PFMEs according to American College of Obstetricians and Gynaecologists (ACOG) guidelines, and this is the first study in our country which thoroughly evaluated response of our patients towards home based PFMEs.

Limitations of this study were; no formal testing by Perineometer or Oxford scale were done and small sample size because majority of the women couldn't be followed and those who were followed, many were not properly doing these exercises. This shows lack of motivation of our women towards these exercises. One of the contributing factor towards lack of motivation could be absence of dedicated antenatal clinics in our country as we couldn't give much detailed information regarding anatomy of pelvic floor muscles and their function due to time constraints, though beneficial role of PFMEs was emphasized.

A good response is expected if women are subjected to "supervised" PFMEs but again, this is not possible for whole pregnant population. Women who are already incontinent and those at high risk of developing this devastating problem could be identified early in the antenatal period and referred for supervised PFMEs.

\section{CONCLUSION}

Home based pelvic floor muscle exercises are very effective in prevention of stress urinary incontinence in only highly motivated patients. There is a need of developing dedicated antenatal clinics for supervised PFMEs in our country for high risk women. Further research regarding effectiveness of home based PFMEs is required if high risk women initially receive information from dedicated antenatal clinics or physiotherapists. 


\section{CONFLICT OF INTEREST}

Declared none.

\section{ACKNOWLEDGEMENTS}

Declared none.

\section{REFERENCES}

[1] Habib M, Chaudhary A. Stain in life: Predisposing risk factors and prophylaxis of urinary incontinence in women. J Soc Obstet Gynaecol Pak 2016; 6(4): 187-92.

[2] Khaldgi B, Shrestha L, Shrestha S. Effectiveness of the antenatal pelvic floor exercise for stress urinary incontinence among the postpartum women. IJSRP 2015; 9(5): e1-3.

[3] Marcin Z, Daria K, Maria M, Daria P, Marcin O, Irena MBA. The impact of pelvic floor exercises on the quality of life of women with urinary incontinence - analysis of pregnancy and the postpartum period. J Nov Physiother Phys Rehabil 2017; 4(2): 35-41.

[4] Jamil A, Sultana R, Feroze S, Quratulain. The prevalence of urinary incontinence in pregnancy. Pak J Surg 2013; 29(1): $66-9$.

[5] Ali HS, Lakhani NA, Sarwar NG. Urinary incontinence three months after delivery; prevalence and risk factors. Professional Med J 2013; 20(4): 530-6.

[6] de Assis LC, Bernardes JM, Pascon Barbosa AM, Santini ACM, Vianna LS, Dias A. Effectiveness of an illustrated home exercise guide on promoting urinary continence during pregnancy: a pragmatic randomized clinical trial. Rev Breas Ginecol Obstet 2015; 37(10): e1-9. DOI: 10.1590/SO100-720320150005361

[7] Cooper HE, Cook T. Antenatal pelvic floor muscle exercises for the prevention and treatment of urinary incontinence in the antenatal and early postnatal period: A critical appraisal of the evidence. ACPRC 2011; 109: 5-13.

[8] Harvey MA. Pelvic floor muscle exercises during and after pregnancy: A systematic review of their role in preventing pelvic floor dysfunction. JOGC 2003; 487-9.
[9] Stafne N, Salvesen KA, Romundstad PR, Torjusen IH, Mørkved S. Does regular exercise including pelvic floor muscle training prevent urinary and anal incontinence during pregnancy? A randomised controlled trial. BJOG 2012; 119(10): 1270-80. DOI: 10.1111/j.1471-0528.2012.03426.x

[10] Boyle R, Hay-Smith EJ, Cody JD, Mørkved S. Pelvic floor muscle training for prevention and treatment of urinary and faecal incontinence in antenatal and postnatal women. Cochrane Database Syst Rev 2012; 10: CD007471. DOI: $10.1002 / 14651858 . C D 007471 . p u b 2$

[11] Boyle R, Hay-Smith EJ, Cody JD, Mørkved S. Pelvic floor muscle training for prevention and treatment of urinary and faecal incontinence in antenatal and postnatal women: A short version Cochrane review. Neurourol Urodyn 2014; 33(3): 269-76. DOI: 10.1002/nau.22402

[12] Sangsawang B, Serisathien Y. Effect of pelvic floor muscle exercise programme on stress urinary incontinence among pregnant women. J Adv Nurs 2012; 68(9): 1997-2007.

DOI: $10.1111 / \mathrm{j} .1365-2648.2011 .05890 . x$

[13] Woodley SJ, Boyle R, Cody JD, Mørkved S, Hay-Smith EJC. Pelvic floor muscle training for prevention and treatment of urinary and faecal incontinence in antenatal and postnatal women. Cochrane Database Syst Rev 2017; 12: CD007471. DOI: 10.1002/14651858.CD007471.pub3

[14] Dumoulin C, Hay-Smith J. Pelvic floor muscle training versus no treatment, or inactive control treatments, for urinary incontinence in women. Cochrane Database Syst Rev 2010; 1: CD005654.

DOI: $10.1002 / 14651858 . C D 005654 . p u b 2$

[15] Talasz H, Himmer-Perschak G, Marth E, Fischer-Colbrie J, Hoefner E, Lechleitner M. Evaluation of pelvic floor muscle function in a random group of adult women in Austria. Int Urogynecol J Pelvic Floor Dysfunct 2008; 19(1): 131-5. DOI: $10.1007 /$ s00192-007-0404-y

[16] Alhund S, Nordgren B, Wilander EL, Wiklund I, Friden C. Is home-based pelvic floor muscle training effective in treatment of urinary incontinence after birth in primiparous women? A randomized controlled trial. Acta Obstet Gynecol Scand 2013; 92: 909-15. DOI: 10.1111/aogs. 12173 